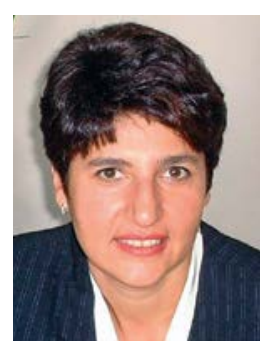

А.Р. Бабаева

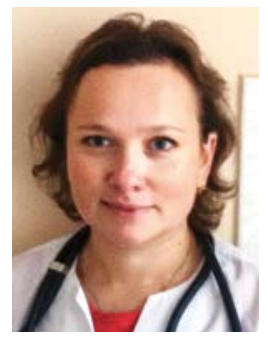

Е.В. Калинина

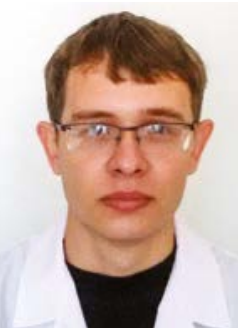

М.С. Звоноренко

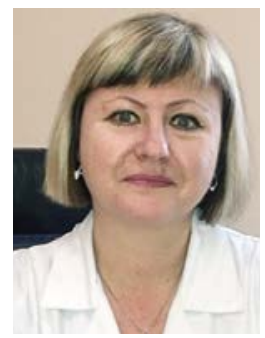

И. В. Кострюкова

Фенотипы спондилоартрита: значение оценки в контексте персонифицированной медицины

\author{
А.Р. Бабаева, А.М.Н., профр., зав. кафельрой \\ Е. В. Калинина, К.М.Н. АОцент, АОцент Кафредры \\ М.С. Звоноренко, аспирант кафредры \\ И. В. Кострюкова, К.м. Н., ассистент кафредры
}

Кафредра фракультетской терапии ФГБОУ ВО «ВолгограАский государственный меАицинский университет» МинзАрава России, г. ВолгограА

\title{
Spondyloarthritis phenotypes: rationale of evaluation in context of personified medicine
}

A.R. Babaeva, E. V. Kalinina, M.S. Zvonorenko, I. V. Kostriukova

Volgograd State Medical University; Volgograd, Russia

Резюме

Статья солержит анализ кАинических фенотипов наиболее значимых нозологических форм спонАимоартрита (СпА)

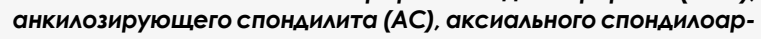
трита (аксСпА), псориатического артрита (ПсА). ПреАставАен полиморфизм СпА с позиции многообразия кАинических проявлений, структурных изменений, рентгенологической, иммунологической и генетической характеристик. Показан вКАаА ОтАеАьнЫХ МеАИаторов воспаления, прежАе всего интерлейкина-17, в развитие структурных поражений. Приведены современные Аанные, касающиеся ассоциации отАельных фенотипов СпА с тканевым антигеном HLA-B27, возрастными и генАерными размичиями, болезнь-специфической коморбидностью. Отражены современные алгоритмы фармакотерапии СпА с учетом эффективности базисных препаратов Аибо резистентности к ним при разных формах Сп А. Подчеркнута важность анализа фенотипа заболевания А^я разработки обоснованной тактики веАения в соответствии с принципами персонифицированной меАицины.

КАЮчевые Слова: спонАилоартрит, фенотип, интерлейкин-17.
Summary

The article contents the analysis of different clinical phenotypes in the most common spondyloarthritis (SpA): ankylosing spondylitis (AS), axial spondylarthritis (axSpA) and psoriatic arthritis (PsA). SpA polymorphism has been discussed on the basis of multiple clinical presentations, structural lesions, radiological, immunological and genetic characteristics. Role of pro-inflammatory agents especially IL-17 in structural progression has been pointed out. Recent data regarding the link between HLA-B27 antigen, gender and age specificity and different clinical manifestation of SpA are presented. Current algorithms for SpA management based on evidence of efficacy SDMARD and/or biologics in separate phenotypes of SpA as well as resistance to DMARD are highlighted. Authors have concluded that meticulous analysis of SpA manifestation and patient's individual profile is critical in rational SpA management according to personified medicine strategy.

Key words: spondyloarthritis, phenotype, interleukin 17.
$\mathrm{C}$ пондилоартриты (СпА) - это гетерогенная группа ревматических заболеваний, характеризующаяся поражением позвоночника, периферических суставов и энтезисов. В группу СпА включены недифференцированный СпА (нСпА), аксиальный СпА (аксСпА), анкилозирующий спондилит (AC), СпА при воспалительных заболеваниях кишечника (ВЗК), СпА при болезни Рейтера и других реактивных артритах (ассоциированных с урогентиальной, кишечной либо респираторной инфекцией), псориатический артрит (ПсА) $[1,3,6]$.

Объединяют эти заболевания общие клинические проявления, рентгенологические признаки, генетические и иммунологические особенности. При СпА различного генеза присутствуют такие общие клинические признаки, как хроническая воспалительная боль в спине, периферический артрит с преимущественным поражением суставов нижних конечностей по типу олигоартрита, частое вовлечение периартикулярных тканей и энтезисов, наличие внесуставных проявлений в виде поражения глаз (передний увеит, эписклерит), кожи (дермопатия, псориаз), кишечника (эрозивно-язвенное поражение слизистой). Рентгенологическая картина СпА характеризуется сакроилеитом, оссификацией сухожильно-связочного аппарата, образованием синдесмофитов в позвоночнике [7]. При разных формах СпА отсутствует такой иммунологический феномен, как ревматоидный фактор, представляющий собой антитела к Fc-фрагменту иммуноглобулина G. Наряду с этим установлена ассоциация между наличием тканевого антигена HLA-B27 и развитием Сп А. Генетическая предрасположенность к СпА подтверждается и частым семейным анамнезом при этом заболевании.

Сходные клинические, рентгенологические и генетические признаки связаны с общими механизмами иммунопатологического и воспалительного процессов при разных формах Сп А. По современным представлениям, CD $4^{+}$T-хелперы (Th) играют важную регуляторную роль в инициации и поддержании иммунного ответа $[4,21]$. Различные субпопуляции Т-хелперов отвечают за отдельные механизмы иммунопетогенеза при ревматических процессах. Так, активированные ИЛ-12 Тh1-клетки синтезируют интерферон- $\gamma(И Ф Н-\gamma)$ 
и опосредуют клеточные иммунные реакции. Th2-клетки секретируют ИЛ-4 и ИЛ-13 и в большей степени влияют на реализацию гуморального иммунного ответа. Особый интерес представляет субпопуляция Th17, которая вырабатывает широкий спектр цитокинов: ИЛ-17А, ИЛ-17F, ИЛ-21, ИЛ-22. Установлено, что активация этой субпопуляции играет важную роль в патогенезе иммуновоспалительного процесса, прежде всего при СпА. В последние годы особое внимание уделяется изучению биологической роли ИЛ-17А. Было показано, что этот цитокин усиливает экспрессию других медиаторов воспаления и хемокинов. Он усиливает синтез матриксных металлопротеаз, а также дифференцировку остеокластов за счет активации синтеза RANKL или экспрессии RANK на предшественниках остеокластов. Указанный механизм объясняет влияние ИЛ-17А на процессы суставной деструкции при ревматических заболеваниях, прежде всего при ПсА [2]. Вместе с тем многочисленные исследования демонстрируют патогенетическую роль ИЛ-17А в остеопролиферации и остеогенезе при СпА [19, 20]. Доказано, что ИЛ-17А стимулирует остеогенез путем усиления дифференцировки остеобластов из стволовых мезенхимальных клеток с последующей активацией дифференцированных остебластов под влиянием системы JAK2 / STAT3 [21].

Для всех форм СпА характерна гиперактивация цитокиновой оси «ИЛ-23 - ИЛ-17», хотя различные фенотипы СпА демонстрируют неодинаковый ответ на ингибирование данных цитокинов $[4,20]$. Доказано, что ИЛ-17А — это ключевой медиатор, определяющий манифестацию кожных, суставных и периартикулярных проявлений (энтезитов) при Сп А. При этом увеличение концентрации циркулирующего ИЛ-17А коррелирует с активностью и тяжестью патологического процесса, а хороший ответ на лечение, в том числе с применением ингибиторов $Ф Н О-\alpha$, сочетается со снижением уровня этого цитокина в крови. Напротив, у пациентов, резистентных к ингибиторам ФНО- $\alpha$, обнаружено увеличение циркулирующих Th17- клеток и уровня ИЛ-17А. Следует подчеркнуть, что единственным доказанным предиктором резистентности к ингибиторам ФНО $\alpha$ является высокий базальный уровень ИЛ-17 (более 40 пг/мл, по данным Chen et al.) Вместе с тем, несмотря на гиперэкспрессию ИЛ-17 в пораженных тканях при воспалительных заболеваниях кишечника и увеите, применение ингибиторов ИЛ-17 не приводит к существенному улучшению при указанных клинических проявлениях СпА [20]. Указанное несоответствие говорит о том, что биологические эффекты ключевых провоспалительных цитокинов недостаточно раскрыты, особенно в плане их влияния на тканевое повреждение при разных фенотипах СпА.

С другой стороны, общие клинические и иммунологические проявления делают обоснованными унифицированные подходы к немедикаментозной и медикаментозной терапии СпА [1].

Вместе с тем существуют принципиальные различия в манифестации отдельных форм СпА, в их клиниколабораторных и рентгенологических особенностях, что и послужило основанием к разделению СпА на самостоятельные нозологические единицы. Кроме того, каждая из форм СпА характеризуется полиморфизмом клинической картины, различными темпами прогрессирования суставных поражений, неодинаковым ответом на болезнь-модифицирующую и противовоспалительную терапию. Важный вклад в реализацию этого полиморфизма наряду с генетическим профилем вносят экзогенные факторы, конституциональные особенности пациента, коморбидная патология. В связи с этим особый интерес представляет анализ фенотипов $\mathrm{AC}$, аксСпА, ПсА как наиболее частых форм СпА, имеющих большое медицинское и социальное значение.

Фенотипы АС. Анкилозирующий спондилит (AC) представляет собой хроническое воспалительное заболевание из группы спондилоартритов (СпА), которое характеризуется обязательным поражением крестцовоподвздошных суставов (КПС) и (или) позвоночника, приводящим к разви- тию анкилозов. При АС наблюдается частое вовлечение в патологический процесс энтезисов и периферических суставов. Прогрессирование заболевания обусловлено пролиферацией костной ткани, что проявляется ростом синдесмофитов и (или) энтезофитов с последующим анкилозированием позвоночника и КПС $[5,6]$. Следует подчеркнуть, что с 2019 года термины «рентгенологический аксиальный спондилоартрит» и «анкилозирующийй спондилит» считаются взаимозаменяемыми [3].

Достоверный диагноз АС может быть установлен в соответствии с модифицированными Нью-йоркскими критериями (van der Linden, 1984), которые включают три клинических критерия и один рентгенологический. К клиническим относятся:

1. боль в нижней части спины длительностью более 3 месяцев, уменьшающаяся после физических упражнений, но сохраняющаяся в покое;

2. ограничение движений в поясничном отделе позвоночника в сагитальной и во фронтальной плоскостях;

3. ограничение дыхательной экскурсии грудной клетки в сравнении с показателями у здоровых лиц.

Один рентгенологический критерий - наличие сакроилеита двухстороннего II-IV стадии, одностороннего III-IV стадии.

Правило пользования: один клинический плюс один рентгенологический критерии позволяют установить достоверный $\mathrm{AC}$; только клинические критерии либо только рентгенологический критерий - вероятный АС. Активность АС и аскСпА следует оценивать по индексам BASDAI и ASDAS (последнему отдается предпочтение, так как он включает лабораторные показатели СРП или СОЭ), которые позволяют верифицировать не только тяжесть заболевания, но и эффективность проводимой терапии $[5,17]$.

В настоящее время накоплено много клинических данных, касающихся особенностей течения АС в зависимости от пола, возраста дебюта заболевания, генетического профиля пациента. Как известно, АC чаще поражает 
мужчин, чем женщин (соотношение $1: 3)$, пик заболеваемости наблюдается в возрасте от 20-30 лет, экспрессия антигена HLA-B27 у лиц с АC достигает $90 \%$. Установлена связь между тяжестью заболевания и темпом прогрессирования, с одной стороны, и фенотипом пациента, с другой. Так, у лиц мужского пола - носителей антигена HLA-B27 чаще развивается аксиальная форма поражения, причем ранний дебют заболевания ассоциирован с более быстрым прогрессированием и неблагоприятным течением, частым поражением внесуставных тканей. У женщин, напротив, чаще, чем у мужчин, регистрируется $\mathrm{AC} \mathrm{с} \mathrm{вовлечением} \mathrm{периферических}$ суставов. При этом нередко имеют место высокая активность заболевания, энтезиты и дактилиты, но темпы прогрессирования сакроилеита и спондилита могут быть невыраженными. Необходимо подчеркнуть, что частым осложнением АС является остеопороз тел позвонков с развитием компрессионных переломов.

Особый вариант артрита при AC - это коксит, который наряду с энтезитами и дактилитами рассматривается как фактор активности и неблагоприятного прогноза АС. Следует подчеркнуть, что рентгенологические признаки коксита при АС сходны с таковыми при остеоартрите: это сужение суставной щели, остеофиты, кисты головки бедра и (или) вертлужной впадины. Редко наблюдаются эрозии, некрозы и анкилоз [7]. В целом внеаксиальные проявления (коксит, другие периферические артриты, энтезиты, дактилиты) чаще возникают у HLA-B27-позитивных пациентов и ассоциированы с более высокой активностью и прогрессирующим сакроилеитом. Наряду с этим АC характеризуется внескелетными проявлениями, наиболее частым из которых является передний увеит (иридоциклит), который диагностируется у трети пациентов - как правило, носителей антигена HLA-B27. Из системных проявлений следует отметить воспалительное поражение сердца и аорты, которое проявляется клинически развитием атриовентрикулярной блокады и аортальной регургитации вследствие аортита с вовлечением аортального клапана, реже диагностируется адгезивный перикардит. К внескелетным проявлениям АС следует отнести и поражение кожи - псориаз, а также воспалительные заболевания кишечника (язвенный колит, болезнь Крона). Присутствие этих феноменов говорит о перекресте между различными формами СпА и подтверждает их патогенетическую близость [5, 24].

Ассоциация между СпА-связанной коморбидностью и формой СпА, а именно наличием $\mathrm{AC}$, недифференцированного СпА и ПсА, была изучена в большом когортном исследовании на основании данных шведского регистра СпА (более 14 тысяч пациентов). Авторы учитывали наличие внесклетных проявлений: воспалительных заболеваний кишечника, псориаза, увеита, а также сердечно-сосудистых проявлений (атриоветрикулярной блокады, аортальной регургитации). Было показано, что у пациентов с разными формами СпА СпА-обусловленная коморбидность наблюдалась значительно чаще, чем в группе контроля. Наиболее часто внескелетные проявления регистрировались в группе $\mathrm{AC}$, затем по частоте поражений внутренних органов следовал недифференцированный СпА, тогда как ПсА оказался на последнем месте по частоте манифестации указанных проявлений. Полученные данные позволили авторам сделать заключение о том, что АС и ндСпА фенотипически ближе друг к другу, нежели ПсА [10].

Выделение различных клиникогенетических фенотипов АС имеет важное практическое значение, так как позволяет объективизировать риск неблагоприятных исходов при этом заболевании, а также применить рациональную терапию уже на ранних стадиях заболевания. Так, согласно современным рекомендациям, наличие энтезитов, дактилитов, коксита, поражения глаз требует активной болезнь-модифицирующей терапии с применением биологических агентов, предпочтительно ингибиторов ИЛ-17. При наличии периферических артритов эффективно лечение сульфасалазином, но рекомендованы высокие дозы - не менее 3 г в сутки. По мнению ряда экспертов, назна- чение сульфасалазина на стадии недифференцированного артрита оправданно его положительным влиянием на активность заболевания, а также на предупреждение развития увеита. Важно подчеркнуть, что современные рекомендации рассматривают сульфасалазин в базисной терапии исключительно периферической формы АС.

Таким образом, выбор медикаментозной терапии зависит от фенотипа АC. Анализ клинических особенностей заболевания наряду с возрастной, гендерной и генетической характеристиками пациента должен быть положен в основу персонифицированного лечения АC.

Фенотипы нрСпА. Понятие «нерентгенологического СПА» (нрСпА) было введено группой экспертов ASAS в связи с тем, что значительная часть пациентов с хронической воспалительной болью в спине и другими признаками СпА не соответствует модифицированным Нью-йоркским критериям AC, так как у этих пациентов нет обязательных рентгенологических признаков сакроилеита и (или) спондилита [17]. Важность такого решения заключается в том, что нрСпА может быть ранней стадией АС (примерно в $60 \%$ случаев) и своевременное лечение позволяет замедлить прогрессию заболевания. В тех случаях, когда не наблюдается трансформации нрСпА в АС, нрСпА рассматривается как самостоятельная нозологическая форма, требующая не менее серьезного внимания [24]. Следует отметить, что нрСпА традиционно подразделяется на аксиальный (аксСпА) и периферический (пСпА) в зависимости от наличия поражения периферических суставов. Для каждого из этих фенотипов предложены четкие классификационные критерии ASAS в 2011 году [23].

Фенотип аксСпА наблюдается у $70-80 \%$ пациентов, обычно у мужчин - носителей гена гистосовместимости человека HLA-B27. Особенностью аксиальной формы поражения являются более упорные и выраженные боли и (или) скованность в позвоночнике, симметричный сакроилеит, по данным МРТ, наличие системных 
проявлений (слабость, повышение температуры тела, снижение веса, ускорение СОЭ, повышение уровня С-реактивного белка), выраженное локальное воспаление в тканях опорно-двигательного аппарата (боль, отек, гипертермия, нарушение функции), чаще формируются анкилозы позвоночника и суставов, а также экзостозы. Чаще всего переходит в рентегнологический аксиальный спондилоартрит. Пациенты с системными проявлениями хорошо отвечают на лечение НПВС, а также НПВП в сочетании с ингибиторами ФНО- $\alpha$.

Фенотип аксиального СпА без системных проявлений может быть диагностирован в 20-30\% случаев, чаще у женщин и у HLA-B27негативных лиц. Особенностью формы является выраженное локальное воспаление в отсутствие признаков системного воспалительного процесса. Есть работы, свидетельствующие о том, что пациенты плохо отвечают на лечение НПВП и ингибиторами ФНО- $\alpha$, но при этом у них реже развиваются анкилозы и «рентегенологический» Сп А.

Периферический спондилоартрит считается вариантом СпА в том случае, если у пациента не было в анамнезе и нет в настоящее время типичной воспалительной боли в спине и доказанного спондилита. Заболевание протекает с преимущественным поражением периферических суставов, однако, согласно классификационным критериям периферического СпА, допускается наличие сакроилеита [23]. Наиболее частым вариантом периферического СпА является псориатический артрит (ПсА) - хроническое воспалительное заболевание из группы спондилоартритов, характеризующееся поражением суставов, позвоночника, энтезисов и ассоциированное с псориазом или его наличием у кровных родственников. Поражение периферических суставов (коленные, голеностопные, локтевые, лучезапястные, суставы стоп и кистей) при аксСпА входит составляющей частью в этот вариант СпА и характеризует распространенность патологического процесса $[2,5]$.
Значение HLA-B27 в клинике и характеристике СпА изучено в работе J. Paramatra et al. Авторы поставили задачу найти клинические различия между HLA-B27-позитивными и HLA-B27-негативными пациентами с достоверным диагнозом аксиального и периферического СпА (критерии ASAS, 2011). Было показано, что HLA-B27-позитивные пациенты были моложе, чаще имели хроническую воспалительную боль в спине, семейный анамнез, сакроилеит при рентгенографии, энтезиты и увеиты, но реже - периферические артриты. Авторы отмечают, что использование классификационных критериев ASAS для периферического СпА приводит к искажению клинических данных, а именно к пародоксальному уменьшению частоты рентгенологического сакроилеита и частоты воспалительной боли в спине в группе HLA-B27позитивных пациентов [22].

От чего зависят тяжесть и прогрессия аксСпА, можно ли выделить фенотип с неблагоприятным профилем? Такую задачу поставили F. Constantino и соавт. (2019), которые провели кластерный анализ клинических данных французского регистра DESIR за 5 лет. 586 пациентов с диагнозом «аскСпА» были разделены на два кластера в зависимости от клинической картины заболевания: кластер А включал лиц с изолированной аксиальной формой поражения (A - Axial), кластер В объединял пациентов с сочетанием аксиальной и периферической форм (B - Both). Оказалось, что в динамике наблюдения кластер В демонстрировал устойчивое преобладание частоты периферических проявлений (энтезитов, дактилитов), более высокую активность заболевания, худшие показатели исходов по оценке пациентов, более частое применение традиционных базисных средств и биологических агентов, в то время как кластер А характеризовался более частым обнаружением сакроилеита по данным МРТ и рентгенографии в последующие 2-5 лет. Полученные результаты позволили авторам сделать важное заключение, что, несмотря на менее выраженную активность, изолированный аксСпА приводит к более быстрой прогрессии сакроилеита, тогда как пациенты с пе- риферическими проявлениями требуют более активной болезнь-модифицирующей терапии и демонстрируют худшие исходы [13].

Группа исследователей из Калифорнийского университета провела исследование зависимости морфотипа сакроилеита и поражения углов позвонков, по данным МРТ, от клинического варианта СпА (первичный аксСпА или СпА как форма ПсА). Учитывали симметричность поражения, степень структурных изменений и выраженность воспалительных признаков. Результаты исследования показали, что асимметричный сакроилеит наблюдался значительно реже при первичном аксСпА нежели в группе пациентов с ПсА, при этом в группе аксСпА асимметрия в поражении илеосакральных сочленений наблюдалась чаще у женщин. Наряду с этим обнаружены различия по счету SPARCC, отражающему тяжесть СпA, а также по выраженности признаков отека костного мозга между указанными группами, которые оказались выше у пациентов с первичным аксСпА [9].

Современные международные и национальные клинические рекомендации подчеркивают, что СпА, в том числе нерентгенологический, является потенциально тяжелым заболеванием, требующим мультидисциплинарного ведения пациента. Клинико-анатомические фенотипы, наличие факторов неблагоприятного прогноза, ответ пациента на лечение - важные факторы, которые определяют необходимость эскалационной терапии с применением более эффективных схем инновационной терапии, а также персонифицированного подхода к патогенетическому лечению $[6,12,17]$.

Псориатический артрит (ПсА) это хроническое прогрессирующее заболевание из группы спондилоартритов, возникновение которого ассоциировано с псориазом. Патологический процесс при этом проявляется в виде эрозивного артрита, энтезита, внутрисуставного остеолиза и спондилоартрита. Широкий диапазон проявлений суставного синдрома при ПсА способствовал выделению отдельных клинико-анатомических вариантов заболевания. 


\section{Клинические фенотипы ПсА} представлены следующими формами: дистальный артрит, асимметричный олигоартрит (моноартрит), спондилит (сакроилеит), ревматоидоподобная форма, мутилирующий артрит (остеолитический вариант ПсА) $[5,6]$.

Дистальный ПсА (локализация артрита только в дистальных межфаланговых суставах), по данным разных авторов, наблюдается у 40-73\% больных. Он характеризуется более доброкачественным течением по сравнению с другими клиническими вариантами. Боли в суставах обычно слабо выражены, утренняя скованность кратковременная, функциональная недостаточность практически не развивается. Имеет место поражение других мелких суставов кистей и стоп без тенденции к вовлечению крупных суставов. Общее состояние больных и функциональные возможности страдают мало. Деструктивный процесс в ДМФ суставах ярко выражен и встречается чаще, чем в других суставах. Эрозии наблюдаются в 2-3 раза чаще, чем в проксимальных межфаланговых суставах (ПМФ), пястно-фаланговых (ПяФ) и плюснефаланговых суставах (ПлФ). Частота анкилозов ДМФ суставов кистей и стоп в несколько раз выше частоты анкилозов любой другой локализации. Характерна взаимосвязь артрита ДМФ с дистрофией ногтевых пластинок. Псориатическая онихопатия по типу наперстковидных вдавлений на поверхности ногтевой пластинки, онихолизиса и онихогрифоза нередко предшествует появлению артрита этой локализации или нарастает в своей интенсивности при его обострении.

Олигоартритический вариант чаще наблюдает у больных вульгарным псориазом. Локализация воспалительного процесса в ограниченном числе суставов является характерной чертой ПсА на протяжении всего заболевания. Наиболее часто поражаемые суставы - голеностопные, коленные. Нет выраженных лабораторных изменений - показатели СОЭ, С-реактивного белка нормальные. Артрит отличается торпидностью к антивоспалительной терапии, включая локальную терапию пролонгированными глюкокортикоидами.
Остеолитический вариант множественный и ярко выраженный внутрисуставной остеолиз, локализуется в мелких суставах кистей и стоп, включая ДМФ, ПМФ, МФ первых пальцев кистей и стоп, Пл $Ф$. Внутрисуставной остеолиз является одним из наиболее значимых симптомов ПсА, он придает этому заболеванию столь характерную картину, которая не встречается при других заболеваниях. Внутрисуставной остеолиз обычно локализуется в мелких суставах кистей и стоп, включая ДМФ, ПМФ, МФ суставы первых пальцев кистей и стоп, ПлФ. Лизис больших участков костной ткани приводит к обезображивающему (мутилирующему) артриту с укорочением пальцев, разнонаправленными подвывихами, симптомами разболтанного пальца. Характерно сочетание выраженного остеолиза с ремодуляцией костной ткани, которая проявляется анкилозами суставов и периоститами. Может быть акральный остеолиз, когда деструкции подвергается ногтевая бугристость дистальной фаланги, в результате уменьшается площадь ногтевой пластинки и происходит изменение пальцев, принимающих вид барабанных палочек.

Полиартритический (ревматоидоподобный) ПсА протекает с вовлечением большого числа крупных и мелких суставов и более, чем другие варианты, сближается с РА. Полиартрит может носить генерализованный характер. Среди мелких суставов наибольшую тропность имеют дистальные межфаланговые суставы, затем пястно-фаланговые и плюснефаланговые суставы, а среди крупных - коленные и голеностопные. С высокой частотой наблюдается артрит межфаланговых суставов первых пальцев кистей и стоп. Нередко вовлекаются височно-нижнечелюстные, грудино-ключичные и грудино-реберные суставы, что обычно ассоциируется с поражением позвоночника.

Псориатический сакроилеит характеризуется поражением крестцово-подвздошных сочленений и позвоночника. Частота рентгенологически доказанного сакроилеита, по разным данным, колеблется от 19 до $85 \%$. Следует подчеркнуть, что сакроилеит при псориазе часто протекает латентно, не давая типичной картины воспалительной боли в нижней части спины. Псориатический сакроилеит, в отличие от $\mathrm{AC}$, обычно является асимметричным, что проявляется не только односторонним поражением, но и разной рентгенологической стадией при двухстороннем процессе. Он чаще является единственным проявлением поражения осевого скелета без тенденции к распространению патологических изменений на вышележащие его отделы (изолированный псориатический сакроилеит). При тяжелом распространенном псориазе сакроилеит выявляется намного чаще, чем при ограниченном кожном синдроме. Так, крестцово-подвздошный анкилоз в 20 раз чаще встречается при пустулезном псориазе или генерализованном экссудативном псориазе. Наряду с этим необходимо подчеркнуть, что IV стадия сакроилеита (полный анкилоз) при ПсА наблюдается реже, чем при АС, и, как правило, только у мужчин.

Псориатический спондилит, частота обнаружения которого колеблется от 9 до 50-60\%, характеризуется болью, ригидностью и ограничением подвижности в позвоночнике, как правило, без выраженной его деформации. Возможно изолированное поражение позвоночника в отсутствие сакроилеита и периферического артрита. Не всегда тяжесть рентгенологических изменений коррелирует с клиническими проявлениями: у некоторых больных даже при наличии множественных синдесмофитов не наблюдалось болей даже при длительно текущем заболевании. При этом, как известно, синдесмофиты при ПсС более грубые, нежели при идиопатическом АС. Выраженность отдельных проявлений ПсС тесно связана с вариантом дебюта заболевания. Дебют ПсА с суставного синдрома или тем более с поражения позвоночника в дальнейшем приводит к яркой симптоматике и быстрому прогрессированию Пс С. Напротив, начало с кожного синдрома сопровождается, как правило, доброкачественным течением анкилозирующего спондилита. ПсС у мужчин встречается в шесть раз чаще, 
чем у женщин, а ярко выраженный $\mathrm{AC}$ на фоне псориаза встречается только у мужчин. Тяжелые формы псориаза рассматриваются как факторы риска развития ПсС, причем шейный отдел позвоночника является излюбленной локализацией ПсС, реже развивается генерализованное поражение осевого скелета [2, 5].

Детальный анализ клинических и радиографических особенностей псориатического СпА в сопоставлении с АC проведен специалистами из Великобритании (D. R. Jadon et al., 2017). Проспективное сравнительное исследование, включавшее 402 пациентов (201 с ПсА и 201 с АС), показало, что почти половина пациентов с ПсА (42,9\%) имели четкие рентгенологические признаки аксиального поражения даже в отсутствие клинических признаков СпА. Следует подчеркнуть, что модифицированным Нью-йоркским критериям АС соответствовало 23,8\% пациентов из группы ПсА, а классификационным критериям CASPAR для ПсA - 24,4\% пациентов из группы АС. При этом активность заболевания, метрологические и функциональные индексы были сходными в сопоставляемых группах. У пациентов с ПсА достоверно реже определялся антиген HLA-B27. Значительная часть пациентов из этой группы (33\%), преимущественно HLA-B27-негативная, имела спондилит без сакроилеита. Полный анкилоз илеосакральных сочленений и грубые синдесмофиты достоверно чаще наблюдались у пациентов с АC. В целом АС характеризовался более тяжелым аксиальным поражением, по данным рентгенологического исследования. Полученные результаты подтверждают высокую частоту перекреста между АС и Пс А. Кроме того, они демонстрируют связь между клинико-морфологическими фенотипами псориатического СпА и генотипом пациентов, позволяют обсуждать этиопатогенетическую разнородность спондилита и сакроилеита при ПсА [16].

Новые аспекты таргетной терапии СпА активно обсуждаются в последние годы. В число препаратов, применяемых для лечения псориатического
СпА, наряду с ингибиторами ИЛ-23/-12 и Ил-17 включены ингибиторы янусных киназ (тофацитиниб) и ингибиторы фосфодиэстеразы (апремиласт). Следует отметить, что в настоящее время продолжаются исследования, направленные на оценку эффективности и безопасности малых молекул в лечении аксиального СпА и АС. В частности, в работе van der Heijede et al. [18] представлены обнадеживающие результаты II фазы испытания тофацитиниба в лечении пациентов с АС. На сегодняшний день получена убедительная доказательная база эффективности этого препарата в лечении кожного псориаза, ПсА, а также СпА на фоне псориаза $[8,11,14]$.

Продолжаются доклинические исследования и клинические испытания новых препаратов из группы ингибиторов ИЛ-17, ингибиторов ИЛ-12/-23, селективных и неселективных ингибиторов ЈАК-киназ. Они проводятся в контексте анализа избирательности влияния того или иного таргетного препарата на отдельные клинические проявления СпА, а следовательно, на эффективность лечения определенного фенотипа заболевания. Такой подход позволит повысить качество лечения пациентов, предотвратить первичную и вторичную рефрактерность к терапии ГИБП, сократить финансовые затраты, повысить приверженность пациентов к лечению и в конечном итоге улучшить исходы при разных формах СпА. Возвращаясь к повседневной клинической практике, необходимо подчеркнуть, что дифференцированная тактика фармакотерапии с учетом фенотипа СпА чрезвычайно важна для реализации современной стратегии лечения до достижения цели.

\section{Список Аитературы}

1. ГайАукова И. 3., Ребров А. П., Аапшина С.А. и Ар. Применение НПВП и ГИБП Аля лечения аксиальных спонаилоартритов. Рекоменаяции Экспертной группы по изучению спонАи^оартритов при Ассоциации ревматологов России // Научно-практическая ревматология. 2017; 55 (5): 474-484.

2. Коротаева Т.В. Перспективы применения ингибиторов интерлейкина-17 - нового к^асса препаратов А^я таргетной терапии псориатического артрита // Научно-практ. ревмато^огия. 2016; 54 (3): 1-5.
3. В.И. Мазуров, И.З Гайдукова. Современная концепция спонАимоартритов. Opinion Leader № 9 (27) 2019. С. 18-29.

4. Насонов Е.^. Новые возможности фармакотерапии иммуновоспалительных ревматических заболеваний: фоккус на ингибиторы интерлейкина 17 // Научно-практ. ревматология. 2017; (1): 68-86.

5. Ревматология. КАинические лекции / ПоА рел. профо. В.В. Балокина. М. Аитература 2012-592 с.

6. Российские кАинические рекоменАации «Ревматология). ПоА реА. акаА. РАНЕ.А. Насонова. ГЭОТАР-МеАИа, 2017. 464 С.

7. Смирнов А.В. Рентгенологическая Аиагнос тика анкилозирующего спонАилита (болезни Бехтерева) - М.: ИМА-ПРЕСС, 2013. 112 с.

8. Asahina A et al. Oral tofacitinib efficacy, safety and tolerability in Japanese patients with moderate to severe plaque psoriasis and psoriatic arthritis: a randomized double-blind phase 3 study. // J Dermatol 2016; 43: 1311-16.

9. Baraliakos X. et al. Does axial spondyloartritis phe notype correlate with imaging morphotype? //DOl: 10/1136/annrheumdis-2017-eular-3681.

10. Bengtsoon K. et al. How strong are the associations of spondyloarthritis-related co-morbidities with ankylosing spondylitis, psoriatic arthritis and undifferentiated spondyloarthritis? A registry-based study from Sweden.// DOI: 10/1136/ annrheumdis-2017-eular. 1255.

11. Clark JD et al. Discovery and development of JAK inhibitors for inflammatory disease J Med Chem 2014; 57: 5023-38.

12. Combe B. et al. 2016 update of EULAR recommendations for the management of early arthritis // Ann Rheum Dis. 2016; 0: 1-12.

13. Constantino F. et al Cluster-based spondyloarthritis phenotypes defined at baseline are predictive of 5-year severity outcome in the DESIR cohort. DOI: 10/1136/annrheumdis-2019-eular.3307.

14. Gao W. et al. Tofacitinib regulates synovial inflammation in psoriatic arthritis, inhibiting STAT activation and induction of negative feedback inhibitors. // Ann Rheum Dis 2016; 75: 311-15.

15. Gossec L. et al. EULAR recommendations for the management of psoriatic arthritis with pharmacological therapies: 2015 update // Ann. Rheum. Dis. 2015; 0: 1-12.

16. Jadon DR et al. Axial disease in psoriatic arthritis study: defining the clinical and radiographic phenotype in psoriatic spondyloarthritis// Ann Rheum Dis 2017: 76: 701-707.

17. van der Heijde D et al. 2016 update of the ASAS-EU LAR management recommendations for axial spondyloarthritis // Ann Rhem Dis 2017; 0: 1-14.

18. van der Heijde $D$ et al. Tofacitinib in patients with ankylosing spondylitis: a phase2, 16-week randomized, placebo-controlled, dose-ranging study/Ann Rheum Dis 2017; 76: 1340-7.

19. Kaaij $\mathrm{MH}$ et al. The link between angiogenesis and osteogenesis in spondyloarthritis/ DOI: 10/1136-annreumdis-2018-EWRR 2018.116.

20. McGonagle DG et al. The role of IL-17 in axial spondyloarthritis and psoriatic arthritis: recent advances and controversies / Ann Rheum Dis 2019; 78: 1167-78.

21. Miceli-Richard C., Dougados M. Tracking JAKs in spondyloarthritis: rationale and expectations Ann Rheum Dis. 2017 Vol. 76, No 8, p. 1325-1326.

22. Paramatra J. et al HLA-B27 positive versus HLA-B27 negative spondyloarthritis: different phenotypes but similar disease burden/ dol 10/1136/annrheumdis-2013-eular. 1586.

23. Rudwaliet $M$. et al. The assessment of Spondyloarthritis international Society classification criteria for peripheral spondyloarthritis and for spondyloarthritis in general // Ann Rheum Dis. 2011; 70: 25-31.

24. Smolen JS et al. / Treating axial spondyloarthritis and peripheral spondyloarthritis, especially psoriatic arthritis, to target: 2017 update of recommendation by international task force // Ann. Rheum. Dis. 2018, 77: 3-11.

Аля цитирования. Бабаева А.Р., Калинина Е. В., Звоноренко М.С., Кострюкова И.В. Фенотипы спонди^оартрита: значение оценки в контексте персонифицированной медицины // Медицинский алфравит. Серия «Ревматология в общей врачебной практике».- 2019.- Т. 2.- 37 (412).- C. 16-21. 